\title{
Teachers' Evaluation of the ILI High Intermediate Book Series through an Eclectic Checklist
}

\author{
Sara Shafiee \\ Department of English, Islamic Azad University, Shiraz Branch, Shiraz, Iran \\ Fatemeh Behjat \\ Department of English, Abadeh Branch, Islamic Azad University, Abadeh, Iran
}

\begin{abstract}
Taking a glance at the plethora of literature on language books evaluation, one can easily explore the critical role being played by coursebooks in language learning contexts. Selecting a course book which fits the requirements of a specific course and aides teaching and learning processes besides offering organization and discipline to an educational course is a critical task carried out by teachers, practitioners or materials developers. One of the most commonly used instruments in evaluating course books in order to adopt or even adapt them, in cases needed, is checklist. Focusing on this recent issue, the present study aimed at evaluating a series of the ILI books which are widely used all around Iran at high-intermediate levels in one of the most well-known national language schools called Iran Language Institute (ILI). The participants were 23 experienced teachers holding BA, MA or PhD at this language school in adult section from different branches in Shiraz. The instrument used in this survey was an eclectic checklist devised and suggested by Yusuf Demir and Abdullah Ertas (2014).
\end{abstract}

Index Terms - checklist evaluation, ILI high intermediate series, ILI language school, textbook evaluation

\section{INTRODUCTION}

On the importance of using textbooks to enhance education, there are plenty of resources. Also there are pieces of research evaluating textbooks for the purpose of selecting the ones that can meet certain course objectives and learners' needs in different contexts. Lots of evaluative frameworks mostly taking the form of a checklist were offered by different researchers as in Williams (1983), Breen and Candlin (1987), Sheldon (1988), McDonough and Shaw (2003), Cunningsworth (1995), and McGrath (2002).Using checklists as a systematic and comprehensive means of evaluating the materials paves the way in doing research in this field. Though in some cases some sorts of modifications are needed. (According to Dickinson, 2010).

ILI (Iran Language Institute) which is evaluated in this study is one of the most well-known language schools in Iran with branches all over the country. High intermediate books which are evaluated through an eclectic checklist devised by Demir \& Ertas (2014), in this study, is a series of three levels among a five-stage categorization of adult section including: basic, elementary, intermediate, high intermediate, and advanced levels.

The present research includes a review of literature on the theoretical and practical aspects of book evaluation with emphasis on checklist evaluation and the ILI book series evaluation, exclusively; followed by the results gained from the evaluation of high-intermediate book series, the discussion and the conclusion based on the findings.

\section{REVIEW OF THE RELATED LITERATURE}

\section{A. Theoretical Considerations}

Evaluation is a key term in the field of materials development. As Tomlinson (2013, p.21) put it, "it is a procedure of measuring the potential value of learning materials which involves making judgments about the effects of the materials on the people using them." This potential value of the materials involves the credibility, flexibility, reliability, validity, the motivating power of the materials, its effect on learners' success in tests (described as a short-term goal) and their achievements in communication skills (termed as a long-term goal), aiding teachers in achieving their instructional and evaluative goals, and above all meeting the administrative needs in terms of standardization in classes, syllabus coverage, and exams preparations (Tomlinson, 2013).

Tomlinson (2013) offered different types of materials evaluation in terms of pre-use evaluation which involves making predictions about the potential value of the materials for their users, whilst-used evaluation which concerns measuring the value of the materials while using them or while observing them being used; this type of evaluation can be considered more objective and reliable since it makes more use of measurement rather than prediction and post-use 
evaluation which he considered as the most valuable type of evaluation but not frequently used since it measures the actual effects of the materials on the users.

Following the point that evaluation is not the assessment of the materials rather the effect of the materials on those who are involved in the course of teaching and learning, he believed since evaluation is being done on users of the materials and involves judgments about the effects of the materials, it is subjective in many ways. In his opinion, using checklists and certain criteria in evaluating the materials reduces the subjectivity and adds to its objectivity and value for generalization; he elaborated on some standard approaches and offered certain criteria for the purpose of materials evaluation. Concerning criteria set for the purpose of textbook evaluation, Cunningsworth (as cited in Richards, 2001) mentioned such criteria as meeting learners' needs, course objectives, users' current and future needs and purposes, facilitating language learning without imposing a rigid method, having a mediating and supporting role for learners, and learning the target language. He also presented a checklist for evaluating textbook materials which considers "aims and approaches, design and organization, language content, skills, topic, methodology, teachers' books and practical considerations" (Cunningsworth, as cited in Richards, 2001, p. 258).

According to Asiyaban and Zamanian (2014), currently most books are produced mainly based on financial and commercial concerns, thus lack the required appropriateness and efficiency concerning the educational purposes and the need to evaluate the books arises from this fact.

\section{B. Empirical Studies}

Most studies regarding book evaluation were conducted through the use of checklists.

Banaruee and Zare-Behtash (2017) evaluated the New Headway Advanced Series (2015), and the Iran Language Institute (ILI) Advanced1 (2008) through a checklist based on the standards of American Council on the Teaching of Foreign Languages (ACTFL). They found New Headway Series more practical than ILI Advanced1 in terms of design and organization, authenticity, attractiveness, functionality, practicality. They concluded that the ILI books are mainly focused on reading and writing and thus less efficient in improving learners' interactional, transactional and communicative needs.

Dickinson (2014) evaluated the materials used to teach a group of young Japanese EFL learners - the coursebook and additional materials of Let's Go 1,its student book (with CD-ROM), workbook, skills bo*ok (with self-study CD), teacher's book, audio CDs, and student and teacher flashcards through a checklist-based materials evaluation scheme using a Likert Scale of agreement to disagreement in terms of general appearance, layout and design, methodology, activities, language skills, language content, topic content, teachability and flexibility, and assessment. The result of the study revealed the appealing appearance of Let's Go lbook, the clear layout of the materials besides being user friendly, the general appropriateness of the language and topic content with occasional adaptation and supplementary materials use requirement. It was also found out that the teaching methodology offered in the teacher's book was not based on any learner- or learning approaches and the structural and grammatical approaches applied in this book did not leave any room for independent learner responses and creativity.

Sadeghi and Mahdipour (2015) evaluated Iran Language Institute Advanced book series in terms of learning objectives based on Bloom's Revised Taxonomy. The cognitive, affective and psychomotor domains were assessed to determine the way critical thinking skills are used and to the range of difference among these books. Results revealed the higher frequency of lower-order cognitive skills (i.e. remembering, understanding and applying) than the higherorder ones (i.e. analyzing, evaluating and creating) in ILI Advanced Series. No significant changes in cognitive skills from Book 1 to Book 2 and Book 3 were observed. The affective skills were not treated differently in ILI advanced series based on the result of the study while in terms of sub categories of psychomotor skills, significant differences among ILI advanced series were observed.

In another study by Shahheidaripour(1998), frameworks proposed by Sheldon (1988) and Skierso (1991) which contain main factors used by teachers and administrators in selecting appropriate textbooks, were adopted to evaluate the ILI (Iran Language Institute) intermediate book series (4-7). The books were evaluated through such factors as: rationale, availability, user's specifications, layout/graphics, accessibility, linkage, selection/grading, physical characteristics, appropriacy, authenticity, sufficiency, cultural bias, educational validity, stimulus/practice/revision, flexibility, guidance, and overall value for money. Concerning these factors, Shahheidaripour (1998), stated that the ILI series in these levels (4-7), lack a clear objective, availability in the public market, specifications as target age, range, culture, probable learning preferences, introductory section and authors' names, use of graphics and pictures, phonetic transcription and complete and easy-to-understand definitions, authentic conversations, target cultural effect, room and time for teachers' flexibility and modifications. The definitions of the vocabularies are often harder to understand than the vocabularies themselves. There are insufficient grammar explanations, writing practice, meaningful exercises, not enough space for note taking, low paper and binding quality. Artificial rather than authentic materials are among the other deficiencies of this book series. On the other hand, in his opinion, the textbook meets the Iranian learners' academic needs and enjoys the advantages of audio-lingual method in sequencing grammar points, drills and repetition. The dominant method affecting the ILI teaching method, curriculum and textbooks is ALM though according to Shahheidaripour (1998), they claim to follow an eclectic method and try to make up for the most deficiencies of this method by employing experienced and skilled teachers. 
Razmjoo and Farmer (2012) also investigated the intermediate level of adults and young learners' books at the ILI in terms of multiple intelligence introduced by Gardner (1983) to evaluate the extent to which their course books represent the Multiple Intelligence Theory. To reach this goal, the checklist developed by Botelho (2003) was used with some modifications for the purpose of localizing based on the focused theory. Analyzing the course books in terms of each intelligence through this checklist, and the frequencies and percentages revealed the dominance of verbal/linguistic, logical/mathematical and visual/spatial types of intelligence compared to the other types. Naturalistic and bodily/kinesthetic types were considered to be the least focused types of intelligence in the ILI intermediate book series. There was a significant difference in terms of logical/mathematical, bodily/kinesthetic, visual/spatial, intrapersonal and musical types between the young and adult section book series. Regarding the percentage of occurrence of verbal/linguistic, interpersonal and naturalistic types of intelligence, no significant difference was reported.

Asyaban and Zamanian (2014), also studied the intermediate ILI English book series through a forty-item questionnaire developed by Litz (2000). The participants were eighty BA and $\mathrm{PhD}$ experienced teachers. Practical considerations including: the reasonability of textbook's price, its accessibility, publishing qualification, textbook package and authors' views on language and methodology ; layout and design; activities; skills; language type; subject and content; and conclusion were the items of the questionnaire based on which the ILI intermediate books were investigated in this study. The results of the study revealed a few deficiencies in most parts of the textbook despite the overall strength of the materials. Teachers' average level of satisfaction and significant difference between male and females' opinions about the "subject and content", "language type", and "conclusion" categories were also shown through this study.

All in all, textbook evaluation seems to be an indispensable part of curriculum and syllabus development and increases the efficiency of the education; Checklists have been widely used to evaluate the textbooks due to their ease of use, reliability and generalizability qualities.

\section{OBJECTIVES OF THE STUDY}

Since the Iran Language Institute (ILI) is considered as one of the most successful governmental language institutes concerning such factors as teachers, syllabus and books in Iran, and most language institutes consider it as a model to design their syllabi and develop their materials, while some complaints on the part of the teachers and learners regarding the materials have been observed, evaluating the textbook being taught at this institute to realize their strength and weak points is of great value. To reach this goal the present study seeks to answer the following question:

1. What are the EFL teachers' perceptions of High Intermediate ILI book series concerning the EFL context of Iran?

\section{METHOD}

\section{A. Participants}

The participants were 23 ILI teachers all with High Intermediate books teaching experience, instructing at different ILI branches in Shiraz.

\section{B. Materials}

ILI (Iran Language Institute) high-intermediate 3-level book series were investigated through an eclectic checklist developed by Demir \& Ertas (2014). Each book includes ten chapters, with the main focus on grammar. Each unit begins with a passage which is aimed at contextualizing the grammar and includes a variety of the vocabularies. The new vocabularies are also listed in a glossary which is offered as a separate supplementary small handbook. A workbook and a CD are also included in the package offered for this high-intermediate course. Despite the grammarbased nature of this book series, the four skills of reading, listening, speaking and writing are involved. Data will be analyzed through descriptive statistics to address the first question of this study and an Independent Sample $t$-test will be run to determine the probable difference between male and female teachers' opinions towards the books used in High Intermediate levels at the ILI.

\section{Instruments}

The eclectic checklist developed by Demir and Ertas (2014) used in this study was considered as the instrument to collect data. It includes four categories as Subjects \& Contents (10 items), Sub-skills \& Skills (25 items), Layout \& Physical Make-up (14 items) and Practical Considerations ( 7 items) which make up 56 items in general. The content validity of the checklist is kept by sticking loyal to the literature as mentioned by Demir and Ertas (2014) and validated through a pilot study by 10 experts in the field as suggested by Demir and Ertas (2014).

In developing this eclectic checklist, 23 evaluation forms and checklists were utilized and combined with the researchers' own items. The draft instrument was reviewed by ELT researchers at a conference of English language teachers' association in Turkey and concerning the feedback received some items were modified.

\section{Data Collection Procedure}

Data were collected through an eclectic checklist devised by Demir \& Ertas (2014) given out to 40 ILI teachers in adult section of the ILI who are capable of teaching high intermediate series in Shiraz. 23 of the questionnaires were 
handed back. The checklists were distributed by the researcher and a brief explanation was given individually or in groups to the colleagues by the researcher. For further comment part of the checklist, the participants were asked to make any further comments in written form.

\section{RESUlTS AND DisCUSSION}

\section{A. Subjects and Contents}

The first category of subjects and contents involves ten questions as follows: the first question asks whether the content reflect the target language culture (American and British)? Most teachers (17 out of 23) answered this question positively. Most teachers in this study believe that the ILI High Intermediate books reflect the target language culture. The second question asks if the book subjects and content are interesting; regarding this question 14 ILI High Intermediate teachers agree that there are some interesting topics though the books need a great revision to bring the topics up-to-date in this regard. Concerning the challenging nature of the content, 18 teachers claim the content of the course book is challenging enough. Most units are developed in a way that require the learners to learn lots of vocabularies and concentrate on new grammatical points to grasp the gist of the unit and to be able to succeed in the final exams based on these books. Next question asks about the motivating nature of the subject and content of the High Intermediate books on which only 11 High Intermediate ILI teachers agree which shows the subject and content as an extrinsic and instrumental type of motivation does not play its role pretty well. The comprehensibility of the thematic content to the students is the other question in the category of subjects and contents. 20 teachers responded positively to this question. This item is possible through teachers' aid which is of great importance in the ILI educational system. Concerning the variety in the subject and content of the course book, 14 teachers think there is enough variety though this variety is not to the interest of the students as they often complain about the burden caused by the variety of grammar points they need to learn. As it was mentioned before in this institute mainly the target language not the target culture is focused, therefore the content seems to be absolutely compatible with learners' L1 culture. 17 out of 23 teacher participated in this study believed in the thematic content culturally appropriateness of the books used in this study. The majority of teachers i.e. 20 out of 23 assert that the texts and topics are free from any kind of discrimination. Following the Iranian cultural etiquettes, it seems the ILI high intermediate books do not involve discriminations of any kind. On the relationship between the content of the course book and the real life situation, there seems to be sufficient relevance since most passages and listening materials of the book are claimed to be extracted from the newspapers, magazines, journals and news excerpts, therefore, the follow-up discussions based on them involve real life practice of the language; besides, most teachers tend to require the students to make real life questions relevant to the topics as an assignment which reinforces learners' experience of real life practice of the language. 18 ILI teachers agree that there is a relationship between the content of the course book and the real-life situations. Concerning the last question in the first category of the checklist, only 7 teachers believe that the topics and texts in the coursebook include elements from both local and target culture. As it was mentioned earlier, L1 culture i.e. local culture is emphasized in the ILI book series and except some authentic texts and listening parts which involve some target language cultural features, there seems to be no direct exposure to the target language culture.

\section{B. Skills \& Sub-skills}

\section{a. Reading}

This category involves the inclusion of reading, listening, speaking and writing as the four primary skills, and vocabulary, grammar and pronunciation as the sub-skills in the course book.

Concerning the three questions raised in this part, only 7 out of 23 participants in this study approved of the adequacy and appropriateness of the exercises and tasks for improving reading comprehension, 14 teachers suppose that there is a wide range of different reading texts with different subject content, and most teachers (17) consider the reading selections as authentic pieces of language.

Regarding the ILI high intermediate books, since the main concern of these three levels is grammar and all the other skills and sub-skills revolve around grammar, the most prominent part of the books content in these levels is the subskill of grammar. Each unit includes a reading passage with the focus on the grammar point of the very unit and the variety of the topics relies on the variety of the grammatical content. Most passages are claimed to be extracted from the authentic articles and papers.

\section{b. Listening}

Each unit contains one or two listening tasks a chance to reinforce and practice the grammar which involve some follow-up questions to be answered and discussions, paraphrasing run by the teachers. A short description of the content of the listening excerpt and an instruction of the follow up activities is also provided. The questions in this part ask whether the coursebook has appropriate exercises and tasks for improving reading comprehension, if the listening material is well recorded and as authentic as possible and whether the listening material is accompanied by background information, questions and activities which help comprehension. All the three questions were answered positively by 18 teachers.

c. Speaking 
Each listening task is followed by a communication task which requires the students to make use of the newlylearned grammar points and vocabularies to run a discussion in groups. The speaking task is mostly of an open-ended, free discussion and meaningful type. As mentioned earlier a group discussion follows each listening task which involves the individuals, though the teachers can assign individual speaking practice and evaluation tasks. The three questions in this part discuss whether the coursebook includes speech situations relevant to students' background, if the activities are developed to initiate meaningful communication and finally whether the coursebook includes adequate individual and group speaking activities. The first question received 15, the second, 11; and the last, only 8 positive answers respectively.

\section{d. Writing}

Regarding writing skill, in the textbook except the grammar points and the follow-up written exercises, there is no specific practice of writing, though in the workbooks, each unit involves a special punctuation note but not a categorization of different genres with models. The punctuation notes involve great writing tips, however they tend to be confusing for the students in some cases. The writing task is confined to the punctuation note presented in each unit and guided and controlled through the follow-up exercises. (e.g. adding the punctuation marks to the text or identifying the mistakes). This part includes three questions as follows:

1. Are models provided for different genres?

2. Do the tasks have achievable goals and take into consideration learners' capabilities?

3 . Is the practice provided in controlled and guided composition in the early stages?

The first question received 8; the second, 16; and the third one, 13 positive answers.

e. Vocabulary

The sub-skill of vocabulary section of the checklist involves 5 questions which deal with the vocabulary load and if it seems to be reasonable for the students of that level; if there is a good distribution(simple to complex) of vocabulary load across chapters and the whole book; if the vocabulary exercises promote internalization of previously and newly introduced items; if the new vocabulary words are repeated in subsequent lessons to reinforce their meaning and use; and if there is new vocabulary integrated in varying contexts and situations. 17, 11, 14, 11, 14 positive answers were given to these questions by the participants respectively.

With regard to vocabularies, it seems that ILI high intermediate books are full of new words, in the passages, grammar exercises, listening parts and workbook exercises, and sometimes the students complain about the large number of the vocabularies, they are required to bear in mind and their high difficulty level. Sometimes the difficulty level of the vocabularies seem to be much higher than the proficiency level of the students; however the new words are introduced in context which makes it easier for the students to remember, though since the emphasis is put on grammar in high intermediate levels, there seems to be no specific gradation of the vocabularies as it is observed in grammar sequencing and if certain vocabularies are repeated in the following units, it is not with the purpose of vocabulary reinforcement yet a variety of contexts with new words are offered which have been mainly provided to contextualize the grammar.

\section{f. Grammar}

Grammar is the other sub-skill dealt with in this eclectic checklist.

The first question in this part asks whether the grammar points are presented with brief and easy examples and explanations; most teachers (19) agree on this point. Second question considers the primary function of new structures for interaction and communication; 10 teachers suppose the new structures are interactional and communicational. The third question deals with the fact that the structures gradually increase in complexity to suit the growing reading ability of the students; 13 teachers believe in gradual difficulty level increase of the grammar. The fourth question in this part asks about the systematic presentation of the structures besides being contextually meaningful; the majority of the teachers (19) approve of this fact about the ILI high intermediate book series. Next question concerns the issue that whether the grammar points are recycled in the following units. 12 participants answered yes.

As it was mentioned earlier, the high intermediate book series at the ILI are grammar-centered, though the examples provided to contextualize the grammar points seem to be too difficult for the students to grasp, due to the large number of new vocabularies; in most cases, this burden is left on teachers' shoulders to provide the learners with simpler examples while illustrating the grammar points. Some structure tend to be practical for the purpose of communication and interaction while most structures are rarely used in daily conversations or even writing tasks. Since the materials is presented with the focus on grammar in high intermediate levels, a smooth gradation of grammar points seem to be observed ,besides, systematic presentation of the grammar in a meaningful context. The last item of grammar sub-skill in the checklist asks whether the grammar points are recycled in the following units. To answer this question, it is worth mentioning that, the ILI high intermediate books generally contain the whole grammatical points that the students have learned in previous levels of basic to intermediate, in more detail and with occasional introduction of some new grammar points which mostly expand the learners' previous knowledge of grammar.

g. Pronunciation

Pronunciation is another sub-skill which is addressed in the used checklist in the present study.

In this part three questions are raised as follows:

1. Is there sufficient work on recognition and production of stress patterns, intonation and individual sounds? 
2. Are the pronunciation points repeated and reinforced in subsequent lessons?

3. Does the coursebook cover other sub-skills like note-taking, skimming, scanning, inferring meaning, listening for gist, etc.?

All the three pronunciation part questions were answered negatively by the majority of the teachers with only 3,6 , and 7 positive answers given to these three questions respectively.

The last two parts of the checklist deal with the layout and physical make-up of the book and some general considerations are brought into attention as follows:

\section{Layout \& Physical Make-up}

Concerning the layout and physical characteristics of the books in high intermediate level at the ILI, such issues as printing quality, the general appearance of the book, the inclusion of a detailed overview of the functions and structures which will be taught in each unit, the reflection of learners' preference in terms of layout, design, and organization, the inclusion of pictures, diagrams, tables etc. to help the students understand the printed text, and the informative and functional illustrations and the convenience of the books in terms of size and weight, are dealt with.

The first question in this part concerns printing quality which is high in most teachers' opinion (i.e. 19). Second question asks whether the books look interesting and fun most teachers think they do not (i.e. 19).

Regarding the third question the majority of the teachers i.e. 21 assert that the coursebooks include a detailed overview of the functions and structures that will be taught in each unit; a small number of teachers i.e. 6 think the coursebooks reflect learners preferences in terms of layout, design, and organization and that they contain enough pictures, diagrams, tables etc. helping students understand the printed text. 11 teachers believe the illustrations in coursebooks are informative and functional and 18 participants consider the size and weight of the coursebooks convenient for students to handle.

Investigating the ILI high intermediate books in terms of the above mentioned factors, reveal that the books suffer from serious lack of interesting, fun, informative and functional illustrations and pictures except the simple tabulation of grammatical structures which provide the students with a short preview of the grammar content of the unit they are going to study. The general lay out of the books does not look interesting, the size and weight of the books seem inconvenient as well, though the books enjoy the high printing quality and the detailed overview of the structures which are going to be taught.

\section{Practical Considerations}

Regarding the recency of the high intermediate books and their availability, that make up the first two items of the practical considerations of the checklist, 20 teachers think the books are up-to-date and easily accessible. 21 teachers think the books are affordable and provided with supplementary materials. Only 9 teachers out of 23 participants in this study think the coursebooks have supporting online materials/tests and e-format and a similar small number of 7 teachers think the books address different learning styles and strategies. Less than half of the participants i.e. 10 think the activities and exercises introduce the main principles of CLT. 16 teachers assert that the coursebooks include selfassessment parts. 12 participants think the activities can be exploited fully and embrace various methodologies in ELT and the fact that the type of syllabus design used in the book is appropriate for learners. 16 teachers disapproved of the capability of the coursebooks integration into technology, thereby allowing for individual study outside the school. Most teachers in this study i.e. 17 teachers think the high intermediate coursebooks fit curriculum/goals. 16 participants think the objectives are explicitly specified in the coursebook and most teachers i.e. 15 believe the coursebooks are not designed by taking into account the learners' socially and historically English-free status.

Regarding the last part of the eclectic checklist used in this study which addresses some practical considerations:

1. Concerning the recency of the books in high intermediate levels the content has not been revised and brought upto-date for years.

2. The books are only available in local bookstores of the ILI branches not in the market.

3. Most students tend to complain about the high price of the books.

4. The textbooks are offered with the workbooks, CD and a supplementary test books (though the test books are not provided adequately). A separate glossary handbook is also offered with the books for each level.

5. Supporting online materials and mid-term tests are provided in the ILI website.

6. The books in high intermediate levels mainly focus on grammar content which call for the teachers' skill to present the materials in a way which addresses various learning styles and strategies.

7. The ILI book series mainly relies on Audio-lingual approach to learning yet the authorities claim to adopt CLT approach as well, and there are such parts entitled as Communication Practice which include the listening part as well as a follow-up discussion relevant to the grammar content and subject matter.

8. No self-assessment parts are found in evaluated high intermediate book series.

9. Concerning the lack of time and the large amount of the materials presented in each unit, teachers are obliged to stick to the syllabus tightly and there is no room for maneuvering over the materials exploiting various methodologies; moreover the authorities and observers require the teachers to follow the steps presented in teachers manuals tightly and not violate the set syllabus in any ways. Since the associate their success to these rigid rules of presenting and practicing the materials that have been applied for years. 
10. The syllabus design may put pressure on learners in some cases as they complain about the boring and demanding content of the materials and tasks which are to be covered each session, though the final results of learners' successful performance tend to confirm the appropriateness of the syllabus design.

11. In general, ILI classes are believed to be teacher-centered and it does not appear that the students be able to study the books on their own; moreover the listening files are not included in the students CDs though the grammar content and the passages can be reinforced through student CDs, appendices and online provided instructional and evaluative grammar files and vocabulary lists.

12. It seems the books meet the requirements set by materials developers and experts efficiently. Providing the students with a variety of grammar points and vocabularies, besides lively listening, speaking, and reading activities.

13. The objective is stated in the introduction part of the book as: “... providing the Student's Books that serve not only as vehicles for classroom instruction but also as resources for reference and self-study. In each Student's Book, the combination of grammar charts, grammar notes, and appendices provides a complete and invaluable reference guide for the students."

14. Last item in the checklist asks whether the course book has considered the learners' socially and historically English-free status; as it was mentioned earlier, since the ILI is a governmental language institute, the developers have tried to develop the materials with the focus on linguistic aspects of language learning, mainly grammar and vocabularies with restricted inclusion of the target language cultural and social features yet since the new structures are presented in natural context of passage, articles and dialogs, they tend to create a fairly rich source of social and historical aspects of the target language.

\section{Teachers' opinions regarding the high intermediate ILI books in their own words}

There was a part at the end of the checklist for teachers' further comments and criticisms which was completed by some of the participants (12) in this study. What follows is a summary of their responses.

One of the teachers stated that: "the subjects and the pictures are neither fun nor varied enough. And that there is much more focus on the grammar and vocabulary than on the ideas, communication, interaction, listening, speaking and writing skills, and students awareness of the target culture and spoken English."

Another teacher supposes high intermediate books especially the third one are "too difficult for the learners...too many new words."

Some teachers consider the books appropriate for grammar courses. "The book has been designed to develop the learners' grammar. It is actually a grammar course. So, other aspects of language learning have been less dealt with in these textbooks. All the activities center around grammar in high [intermediate] classes at the ILI."

"The series of high intermediate books are totally grammar-based. Students are not motivated to improve other skills. Most often the teacher is the only speaker. Materials are not that interesting."

Some think the books need to be revised and brought up-to-date to meet the present learners' needs. And the fact that the books are not communicative enough despite current emphasis on learning language for communication in the present world of language learning. Lack of time is another matter of complaint expressed by some teachers in this study. "I believe our students certainly need an up-to-date and motivating material to learn well. The existing coursebook is neither encouraging nor appropriate for learning contemporary English."

"High intermediate books are not the type of books recommended for those who are into CLT. They just pressure both teachers and learners into teaching and studying something invalid and outmoded."

"The book seriously lacks communication-based material and activities. The material is old-fashioned and hardly addresses present-day issues and topics e.g. recent electrical devices, late marriage, inflation, new fashion trends, etc."

"It is not communicative at all. Too much grammar is boring. The book is all black and white, so boring. The topics are good, though there is not enough time to fully explore them or let students have discussions."

"In my opinion, only an experienced, enthusiastic teacher can breathe life into these textbooks so that they become less tedious, of course if time allows."

One of the most experienced experts at the ILI besides praising the teachers and the methodology at the ILI, concerning the need for bringing the books up-to-date states: "in the ILI English textbooks many of the items in this checklist are missing and are somehow light and shallow. However, the teachers' roles coupled with the unique methodology makes up for those deficiencies. There seem to be an urgent need to modernize and update them, a process which has already started, and the new books are coming in to use."

Another experienced teacher pinpoints the reason for higher popularity of the ILI advanced books compared to high intermediate ones by saying: "These books have to be revised to better meet the main principles of CLT or they[there] will remain a gap between Intermediate and Advanced levels which sound more appealing to learners."

One of the teachers meticulously leaves comments on different parts of the checklist concerning the ILL high intermediate books as follows:

1) Regarding writing, only production of basic elements of a paragraph is explained and required. The point that is worth mentioning is that the students learn to get their ideas across by incorporating correct structural rules.

2) As with the vocabulary, the movement from simple to complex words is evident in High [Intermediate] 2 and High [Intermediate] 3, but with High [Intermediate] 1, the vocabulary seems to have been sacrificed to grammar in the first 5 or 6 units. 
3) Every lesson is a separate entity standing by itself, irrelevant to the ones preceding or succeeding it, only having to do with the accompanying workbook set exercises related to it.

4) The new vocabulary does not seem to appear in a variety of contexts, but the mere mention of it in one sample context really helps the learners internalize it.

5) It is mostly the teacher's job to present the material beautifully and in the most comprehensive way.

6) What is missing in the complilation [compilation] of the book is pronunciation practice.

7) Apart from the class $\mathrm{CD}$, the students have the reading material recorded on their own $\mathrm{CD}$, and the Research and Planning Department of the institute has devised a supplementary book of exercises, which is offered to students along with the coursebooks.

8) The book does include mid-term self-test and three remedial tests, devised by the Research and Planning Department again. Those appear in the workbook. Also in cases the coursebook offers personality questionnaires through which the students unconsciously use the target structures.

9) The only complaint that learners have is that they have to learn too much grammar; however, the teachers approach may in many cases alleviate the problem.

\section{CONCLUSION}

All course books have some strengths besides some weak points. Teachers and materials developers need to identify the efficiency and deficiencies of the materials they make use of in their teaching context and reinforce the capacities and eradicate the problems to reach the best ends. The high intermediate book series investigated in the present study enjoy an overall success in terms of grammar gradation and sequencing, providing rich authentic context for the grammar and vocabularies, high printing quality, and the detailed overview of the structures which are going to be taught though it requires a great revision in terms of general appearance, inclusion of illustrations, diagrams, tables and providing learners with more opportunities to reinforce their listening, writing skills and pronunciation as a sub-skill.

\section{ACKNOWLEDGEMENTS}

The authors, herewith, would like to express their gratitude towards the Iran Language Institute (ILI) and High Intermediate teachers for their cooperation.

\section{REFERENCES}

[1] Alamri, A. A. M. (2008). An evaluation of the sixth grade English language textbook for Saudi boys' schools. MA thesis, King Saud University.

[2] Asiyaban, A. R., \& Zamanian M. (2014). Scrutinizing the appropriateness of the intermediate ILI English series in the EFL context of Iran. Theory and Practice in Language Studies, 4, 6, 1257-1265.

[3] Atkins, A. (2001). An evaluation of the coursebook used for oral communication one at a privately funded senior high school in Japan [online]. University of Birmingham,UK. Retrieved from www.cels.bham.ac.uk/resources/essays/atkins3.pdf on February 19 th 2010.

[4] Botelho, M. (2003). Multiple intelligence theory in language teaching: An analysis of current textbooks, materials and teachers' perceptions. Pan-Pacific Association of Applied Linguistics 16(1), 73-82.

[5] Breen, M., \& Candlin, C. (1987). "Which materials? A consumer's and designer's guide.” In Sheldon, L.E. (ed.) ELT textbooks and materials: problems in evaluation and development. ELT Documents, 126. London: Modern English Publications/The British Council.

[6] Cunningsworth, A. (1995). Choosing your coursebook. London: Longman.

[7] Demir, Y., \& Ertas, A. (2014). A suggested eclectic checklist for ELT coursebook evaluation. The Reading Matrix, 14, 2, 243252.

[8] Dickinson, P. (2010). Evaluating and adapting materials for young learners.UK: Centre for English Language Studies: The University of Birmingham.

[9] Gardner, H. (1983). Frames of mind: The theory of multiple intelligence. New York: Basic Books.

[10] ILI Research and Planning Department. (2004). Student's book: High-intermediate1-3.Tehran: The Iran Language Institute, the Research and Planning Department of the institute.

[11] Litz, D., (2005). Textbook evaluation and ELT management: A South Korean case study. Asian EFL Journal. Retrieved from. www.asian-efljournal. Com/Litz_thesis.pdf on January $1^{\text {st }} 2018$.

[12] McDonough, J. \& Shaw, C. (2003). Materials and methods in ELT. Oxford: Blackwell.

[13] McGrath, I. (2002). Materials evaluation and design for language teaching. Edinburgh: Edinburgh University Press.

[14] Murdoch, Y. (2000). Evaluation of the coursebooks used in the Chungbuk provincial board of education secondary school teachers' training sessions. Retrieved from www.cels.bham.ac.uk/resources/essays/yvette3.pdf. On January $1^{\text {st }} 2018$.

[15] Razmjoo, S.A., \& Farmer, Z. (2012). On the representation of multiple intelligence types in the ILI intermediate coursebooks: A coursebook evaluation, Iranian Journal of Applied Language Studies, 4,153-188.

[16] Richards, J. C. (2001). Curriculum development in language teaching. New York: Cambridge university press.

[17] Sadeghi, B., \& Mahdipour, N. (2015). Evaluating ILI advanced series through Bloom's revised taxonomy. Science Journal (CSJ), 36, 3, 2248-2260.

[18] Shahheidaripour, Gh. (1998). An evaluative review of a course in English, book \#4. Eric No.: ED500453. Retrieved from https://eric.ed.gov/?id=ED500453. On March $1^{\text {st }} 2018$. 
[19] Sheldon, L. (1988). Evaluating ELT textbooks and materials. ELT Journal, 42(4), 237-246.

[20] Skierso, A. (1991). Textbook selection and evaluation. In M. Celce-Murcia (Ed.), Teaching English as a Second or Foreign Language (2nd ed.).

[21] Tomlinson, B. (2013). Developing materials for language teaching (2nd ed.). London: Bloomsbury.

[22] Williams, D. (1983). Developing criteria for textbook evaluation. ELT Journal, 37(3), 251- 255.

[23] Zare-Behtash, E. \& Banaruee, H. (2017). Critical Evaluation of the New Headway Advanced and the ILI Advanced Series: A comparison of curricular components and CLT objectives based on ACTFL. International Journal of Applied Linguistics \& English Literature, 6(5), 182-190.

Sara Shafiee is a PhD candidate at Shiraz Islamic Azad University. She is currently teaching at the ILI (Iran Language Institute), in adult section, in Shiraz, Iran. She has taught at different language Institutes and Institutes of Higher Education. She has the experience of participating and presenting articles in some conferences and workshops in the field of teaching, besides, publishing articles in national journals. Her research interests are TEFL, TESL, psycholinguistics, culture and discourse analysis.

Fatemeh Behjat is a Ph.D. graduate in TEFL at Islamic Azad University, Shiraz Branch and a faculty member at Islamic Azad University, Abadeh branch, Iran. She also teaches English at Zand Institute of Higher Education and Islamic Azad University in Shiraz. She has an eight-year experience teaching English at the ILI (Iran Language Institute). She has so far presented papers at international conferences at home and abroad, published books on reading comprehension and a couple of articles in language journals. Her main area of interest is teaching and language acquisition. 